\title{
ANALISIS IMPLEMENTASI MODEL PENCITRAAN DAN DAYA SAING INSTITUSIONAL MELALUI MANAJEMEN PENGETAHUAN DAN MODAL SOSIAL
}

\author{
Erna Setijani $^{1 *}$, Chodidjah ${ }^{1}$ \\ ${ }^{1}$ Fakultas Ekonomi dan Bisnis, Universitas Merdeka Malang \\ *erna.setijani@unmer.ac.id
}

\begin{abstract}
:
This study intend to analyse the implementation of institutional image and competitiveness model through knowledge management and social capital. The try out of model supervised periodically for limited small and medium industries in Probolinggo (10 SME's). Based on the primary data collected during implementation and then analyzed by discriptive and parametrical statistic (compare-means) found that there are significancy differences between before and after model implementation. It means, the created model at this study can be categorized as adaptive model for SME's in Probolinggo. Therefore, if we want to build corporate image and business competitiveness, this model strongly recommended to be applied. By this way, the small and medium industries will have good image and adequate business competitiveness at the market. Interestingly, the model at this study as standard model and support previous studies that suggest knowledge management and social capital play an important role to build corporate image dan business competitiveness.
\end{abstract}

Keywords: Institutional Image, Competitiveness, Knowledge Management, Social Capital

\section{PENDAHULUAN}

Beberapa hasil penelitian tentang faktor pendongkrak daya saing telah cukup banyak dipublikasikan. Para peneliti tersebut mengungkapkan bahwa manajemen pengetahuan dengan indikator personal knowledge, job procedures, dan technology berpengaruh nyata terhadap kemampuan berinovasi sekaligus pada meningkatnya daya saing. Sebuah kebutuhan entitas bisnis yang tak terelakkan guna memberikan jaminan pada masa depannya yang lebih sustainable. Karena manakala tidak memiliki daya saing memadai, maka akan mengurangi optimisme pada kemungkinan berkembangnya usaha pada masa mendatang (Kosasih dan Budiani, 2008 dan Cassidy, 2009). Lebih-lebih pada berlangsungnya era kolaborasi dan regionalisasi pasar yang dikenal dengan ASEAN Economic Community akhir-akhir ini.

Tujuan studi dengan uji coba ini adalah untuk mengungkap model pencitraan dan day saing institusional industri kecil dalam persepektif manajemen pengetahuan dan modal sosial yang bersifat standar. Diharapkan, dengan uji coba model tersebut, secara teoritik akan makin khasanah ilmu menejemen khususnya rumpun ilmu manajemen strategi tentang bagaimana membangun pencitraan dan daya saing institusional secara pragmatis.

Selanjutnya, latar belakang dilaksanakannya penelitian ini dipicu oleh fenomena citra produk usaha kecil yang masih bersifat inferior dalam perspektif pasar, lebih-lebih pada berlangsungnya era ASEAN Economic Community sekarang ini. Kedua, menejemennya yang masih kerap bertumpu pada single loop learning. Ketiga, daya saing produknya yang masih relatif rendah yang bisa mempengaruhi kelangsungannya. Karena itu, berdasarkan fenomena-fenomena tersebut penelitian pengembangan model pencitraan institusional dan daya saing dalam pesepektif knowledge management dan modal sosial ini sangatlah mendesak. Namun 
yang paling penting, temuan riset ini akan menjadi hal baru dalam ilmu manajemen tentang salah satu model pencitraan dan daya saing isntitusonal. Bahkan dalam jangka panjang akan memberikan benefit dalam membangun pencitraan dan daya saing produk yang dihasilkannya.

Sebenarnya, studi terkait dengan keunggulan bersaing sebenarnya telah cukup banyak dilakukan oleh para peneliti, lebihlebih di berbagai negara maju. Hal tersebut karena keunggulan besaing merupakan sebuah predikat strategis untuk menjaga sustainability sebuah entitas organisasi, baik komersial maupun non komersial. Penelitian-penelitian yang dilakukan terkait dengan makin banyak faktor yang diteliti. Sebagai misal dengan menggunakan variabel knowledge management dan juga social capital.

Sebagai misal, beberapa hasil riset (Stewart, 2007; Kosasih dan Budiani, 2008 dan Cassidy, 2009) mengungkapkan bahwa knowledge management yang merupakan sebuah pengelolaan pengetahuan yang diukur dengan tiga dimensi yang meliputi personal knowledge, job procedure, dan technology juga berdampak signifikan terhadap inovasi. Tentu pendapat ini harus menjadi kajian serius dalam rangka untuk keberlangsungan sebuah organisasi. Demikian pula talent development sebagai pengelolaan dan pengembangan talenta melalui business coaching, business sharing dan knowledge transfer. Social capital yang wujudnya setiap hubungan yang terjadi dan diikat oleh suatu kepercayaan (trust), kesaling pengertian (mutual understanding), dan nilai-nilai bersama (shared value) yang mengikat anggota kelompok untuk membuat kemungkinan aksi bersama dapat dilakukan secara efisien dan efektif memiliki implikasi positif pada banyak organisasi modern, karena faktanya dapat meningkatkan daya inovasi akhir-akhir ini. Kemudian tentang modal sosial, hasil riset Ramdani (2009) menemukan bahwa modal sosial sebagai serangkaian nilai-nilai atau norma-norma yang diwujudkan dalam perilaku yang dapat mendorong kemampuan dan kapabilitas untuk bekerjasama dan berkoordinasi yang menghasilkan inovasi. Sebelumnya Cohen dan Prusak (2003), dalam hasil risetnya menyimpulkan bahwa modal sosial yang diikat oleh suatu kepercayaan, kesaling pengertian dan nilai-nilai bersama yang mengikat anggota kelompok untuk berprilaku positif dan kreatif.

Modal sosial menggambarkan segala sesuatu yang membuat masyarakat bersekutu untuk mencapai tujuan bersama atas dasar kebersamaan, serta didalamnya diikat oleh nilai-nilai dan norma-norma yang tumbuh dan dipatuhi (Dasgupta dan Serageldin, 1999). Demensi modal sosial inheren dalam struktur relasi sosial dan jaringan sosial di dalam suatu masyarakat yang menciptakan berbagai ragam kewajiban sosial, menciptakan iklim saling percaya, membawa saluran informasi, dan menetapkan normanorma, serta sangsi-sangsi sosial bagi para anggota masyarakat tersebut. Namun demikian Fukuyama (2006) dengan tegas menyatakan, belum tentu norma-norma dan nilai-nilai bersama yang dipedomani sebagai acuan bersikap, bertindak, dan bertingkahlaku itu otomatis menjadi modal sosial. Hasil riset dan beberapa konsep pemikian tersebut merupakan pijakan untuk melakukan penelitian lanjutan terkait dengan daya saing.

Disamping itu, George \& Wesley (2008) mengungkapkan bahwa pencitraan institusional adalah sebuah popularitas positif organisasi yang memiliki dampak luas pada persepsi dan prilaku masyarakat terhadap organisasi yang bersangkutan, bahkan pada keunggulan bersaing secara institusional. Seorang top leader organisasi yang terkenal akan memiliki kontribusi besar pada pencitraan organisasi yang dipimpinnya. Kemasyhuran di luar organisasi akan menambah kekuatan bagi organisasi termasuk pula pada poduk dan jasa yang menjadi luarannya. Tentunya pencitraan institusional tidak hanya dipengaruhi figur pimpinan tetapi juga image produk, akuntabilitas dan modal sosial. Colgate (2009) juga menjelaskan keunggulan bersaing sebagai posisi organisasi unik terhadap pesaingnya. 
Keunggulan bersaing dapat diperoleh sebagian besar dari sumberdaya dan modal. Sumberdaya yang dimaksud adalah kekuatan dan kelemahan kinerja pemasaran, sedangkan modal diartikan sebagai kemampuan perusahaan dalam mengelola sumberdaya yang dimiliki untuk bekerja sama seperti tim kerja dalam satu departemen, atau dengan kata lain tinggi rendahnya kinerja pemasaran akan berpengaruh kepada tinggi rendahnya keunggulan bersaing perusahaan. Dijelaskan lebih lanjut, keunggulan bersaing bisa diciptakan dengan pengetahuan yang benar akan variabel-variabel yang mendahuluinya. Pengukuran keunggulan bersaing dalam penelitian Day dan Wensley (2008) menyatakan ada dua pijakan dalam mencapai keunggulan bersaing yaitu keunggulan posisi yang terdiri dari keunggulan biaya relatif rendah dan keunggulan nilai atau manfaat.

\section{METODE}

Kegiatan penelitian ini menggunakan pendekatan research and development $(R \& D)$ dengan metode eksploratif kuantitatif. Pengumpulan data dilakukan dengan teknik survei, suatu kajian yang mengambil sampel dari satu populasi dengan menggunakan kuesioner sebagai alat pengumpul data pokok. Unit analisisnya, semua usaha kecil di Probolinggo. Kemudian, dari sifat hubungannya dengan variabel lain, terdiri dari variabel eksogen dan variabel endogen. Variabel eksogen adalah variabel yang variasinya mempengaruhi variabel lain, sedangkan variabel endogen adalah variabel yang variasinya dipengaruhi variabel lain. Variabel mediasi sifatnya memperkuat atau memperlemah hubungan antar variabel. Pada penelitian ini manajemen pengetahuan dan modal sosial sebagai variabel eksogen, variabel pencitraan institusional dan keunggulan bersaing sebagai variabel endogen.

Dari telaah pustaka, maka definisi operasional secara lengkap adalah (a) Manajemen pengetahuan adalah sebuah pengelolaan pengetahuan yang diukur dengan tiga dimensi yang meliputi personal knowledge, job procedure, dan technology. (b) Modal Sosial adalah setiap hubungan yang diikat oleh suatu kepercayaan, kesaling pengertian dan nilai-nilai bersama yang mengikat anggota kelompok untuk membuat kemungkinan aksi bersama dilakukan secara efisien dan efektif. (c) Pencitraan Institusional adalah sebuah popularitas positif organisasi yang memiliki dampak luas pada persepsi dan prilaku masyarakat terhadap organisasi yang bersangkutan dan (d) daya saing adalah tingkat posisi organisasi yang unik terhadap pesaingnya dan biasanya dapat diperoleh sebagian besar dari sumberdaya dan pemanfaatan modal.

Penelitian ini menggunakan data primer, yang diperoleh secara langsung dari para responden penelitian. Data primer pada penelitian ini diperoleh dari jawaban yang didapat dari kuesioner yang diberikan kepada responden penelitian, dan hasil dari pengujian yang dilakukan. Jenis data ini didapat langsung dari penyebaran kuesioner kepada pelaku UKM di Kota Probolinggo Jawa Timur. Mengingat jumlah responden yang relatif besar dan untuk mengantisipasi adanya data yang cacat, maka teknik pengumpulan data yang digunakan adalah proportional random sampling yaitu sebuah satuan sampel yang dipilih berdasarkan pertimbangan tertentu dengan tujuan untuk mendapatkan sampel dengan karakteristik tertentu, dengan kuota sampel sebanyak 100 responden. Menurut Sugiyono (2009), mengenai responden yang representatif dengan menggunakan teknik analisis SEM adalah 100-200 orang responden. Karenanya, jumlah responden pada penelitian ini ditentukan 100 responden.

Pada penelitian ini data yang dikumpulkan menggunakan daftar pertanyaan atau kuesioner. Kuesioner merupakan cara pengumpulan data dengan memberikan daftar pertanyaan kepada responden untuk diisi. Pertanyaanpertanyaan yang terdapat di dalam kuesioner dibuat dalam bentuk pertanyaan dengan menggunakan skala 1-10 dari tidak setuju 
sampai sangat setuju. Tentu, instrumen penelitiannya yang sudah teruji validitas dan dan reliabilitasya.

Teknik analisis digunakan untuk menginterpretasikan dan menganalisis data. Analisis data adalah proses penyederhanaan data kedalam bentuk yang lebih mudah dibaca dan diinterpretasikan. Menganalisis model penelitian dengan SEM dapat mengidentifikasi dimensi-dimensi sebuah construct dan pada saat yang sama mengukur pengaruh atau derajat hubungan antar faktor yang telah diidentifikasikan dimensidimensinya itu (Yamin \& Kurniawan, 2009). Penelitian ini akan menggunakan 2 macam teknik analisis yaitu (a) Factor Analysis pada SEM yang digunakan untuk mengkonfirmasikan faktor-faktor yang paling dominant dalam satu kelompok variabel dan (b) Regression Weight Analysis pada SEM yang digunakan untuk confirmatory meneliti seberapa besar hubungan antar variabel. Tahapan terakhir pada penelitian ini adalah uji coba dan standardisasi model. Sedangkan alat analisisnya menggunakan teknik analisis diskriminan

\section{HASIL DAN PEMBAHASAN}

Berdasarkan survey hasil penelitian, jumlah pelaku IKM di Kota Probolinggo ini berjumlah 385 unit IKM (Dinas Koperasi, Energi Mineral, Industri dan Perdagangan Kota Probolinggo, 2015). Keberadaan IKM tersebut tersebar di 5 (lima) wilayah kecamatan (Mayangan, Wonoasih, Kanigaran, Kademangan dan Kadopok yang meliputi 29 kelurahan. Industri tersebut meliputi industri kayu, Industri mineral non logam, Industri barang logam, Industri makanan dan minuman, Industri tekstil, Industri kulit, dan Industri keramik.

\section{Identitas UKM Uji Coba Model}

Jumlah entitas usaha pada kegiatan tempat uji coba model pada penelitian ini sebanyak 10 unit UKM yang tersebar pada 5 (lima) Kecamatan di Kota Probolinggo. Berdasarkan hasil penelitian diperoleh bahwa para responden yang terdiri dari para pelaku usaha dengan proporsi $60 \%$ pelaku UKM laki-laki dan $40 \%$ perempuan, yang secara lebih rinci dapat dijelaskan pada tabel 1 berikut:

Tabel 1. Identitas Responden

\begin{tabular}{llll}
\hline No. & $\begin{array}{l}\text { Jenis } \\
\text { Kelamin }\end{array}$ & Jumlah & Prosentase \\
\hline 1 & Laki-Laki & 6 orang & $60 \%$ \\
2 & Perempuan & 4 orang & $40 \%$ \\
\hline Jumlah & 10 orang & $100 \%$ \\
\hline
\end{tabular}

Sumber: Data Primer Diolah, 2016

Berdasarkan hasil uji model teoritik pada penelitian tahap pertama, dengan memanfaatkan analisis structural equation model (SEM) yang telah dilakukan, model yang telah didisain pada tahun pertama dinyatakan sesuai (fit) untuk kegiatan penelitian ini. Hal itu karena semua hasil evaluasi uji goodness of fit index ternyata baik dan hanya satu berkategori marginal yaitu pada kriteria AGFI, yang nilainya kurang dari 0.90 . Hal tidak menggugurkan modela karena menurut Sugiyono (2013) menyatakan bahwa jika beberapa kriteria sudah memenuhi cut of value, maka model tersebut sudah dapat dinyatakan baik. Apalagi pada uji model ini hanya terdapat 1 (satu) kriteria saja yang kurang memenuhi cut of value, maka dapat disimpulkan bahwa model yang telah didisain sebelumnya dapat dinyatakan sebagai model akhir, yang akan digunakan sebagi uji coba pada UKM terpilih.

Tabel 2. Hasil Uji kesesuaian Model Penelitian

\begin{tabular}{llll}
\hline $\begin{array}{l}\text { Goodness of } \\
\text { Fit Index }\end{array}$ & $\begin{array}{l}\text { Cut- } \\
\text { off } \\
\text { Value }\end{array}$ & $\begin{array}{l}\text { Hasil } \\
\text { Analisis }\end{array}$ & $\begin{array}{l}\text { Evaluasi } \\
\text { Model }\end{array}$ \\
\hline $\begin{array}{l}\mathrm{X}^{2} \text { - Chi- } \\
\text { square }\end{array}$ & $\begin{array}{l}\mathrm{P}=5 \%, \\
\text { Chi- } \\
\text { Square }\end{array}$ & 38.113 & Baik \\
& 68.673 & & \\
\hline $\begin{array}{l}\text { Signifinacance } \\
\text { Probability }\end{array}$ & $\geq 0.05$ & 0.405 & Baik \\
RMSEA & $\leq 0.08$ & 0.039 & Baik \\
\hline GFI & $\geq 0.90$ & 0.939 & Baik \\
\hline AGFI & $\geq 0.90$ & 0.889 & Marginal \\
\hline CMIN/DF & $\leq 2.00$ & 1.161 & Baik
\end{tabular}




$\begin{array}{llll}\text { TLI } & \geq 0.95 & 0.998 & \text { Baik } \\ \text { CFI } & \geq 0.95 & 0.990 & \text { Baik }\end{array}$

Sumber :data pimer diolah, 2016

Dengan demikian, model teoritik pengembangan pencitraan korporasi dan daya saing dalam persepektif manajemen pengetahuan dan modal sosial dapat disusun sebagaimana yang telah digambarkan pada kerangka model teoritik, yang telah disusun peneliti pada gambar 1, adalah sebagai berikut.

Gambar 1. Model Teoritik Pencitraan dan Daya Saing

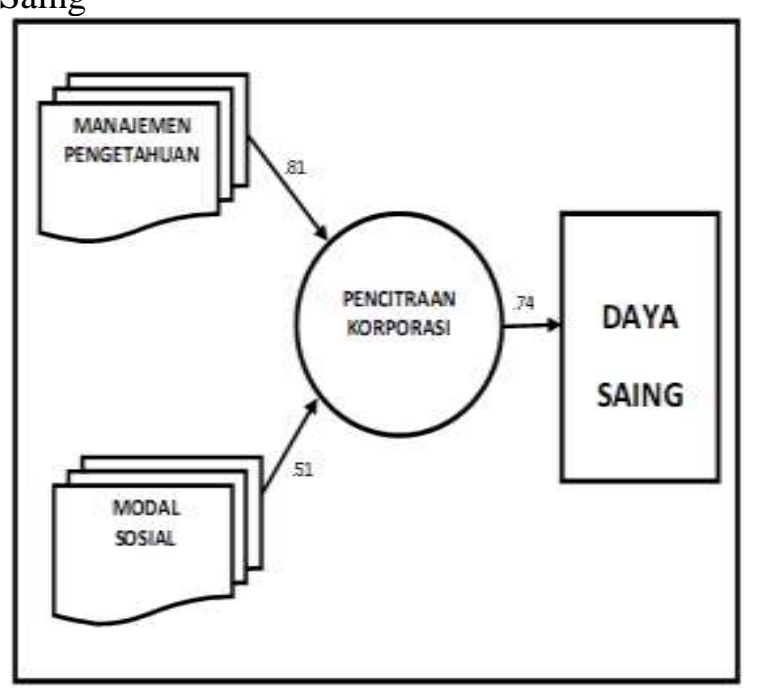

Sumber: Hasil Olah Data Primer, 2016

Berdasarkan gambar 1 terungkap bahwa baik manajemen pengetahuan dan modal sosial mempunyai koefisien pengaruh yang cukup besar, yaitu masing-masing 0.81 dan 0.51. Bahkan pencitraan korporasi juga berpengaruh kuat dengan koefisien sebesar 0.74 terhadap daya saing. Maknanya, model tersebut tidak hanya sesuai dengan penelitian ini, tetapi juga berpengaruh nyata terhadap peningkatan daya saing usaha. Selanjutnya, model teoritik tersebut diujicobakan pada 10 (sepuluh) sampel UKM di wilayah Kota Probolinggo, yang pelaksanannya disertai dengan pelatihan dan pendampingan berkala dan dalam kurun waktu selama 5 (lima) bulan terungkap bahwa omset penjualannya mengalami peningkatan yang relatif signifikan.
Berdasarkan pelaksanaan data hasil uji coba model tersebut akan ditampilkan perbandingan rerata omset penjualan antara sebelum dan sesudah uji coba model sebaimana tertera pada gambar 2, sebagai berikut.

Gambar 2. Perbandingan omset penjualan sebelum dan sesudah uji coba model

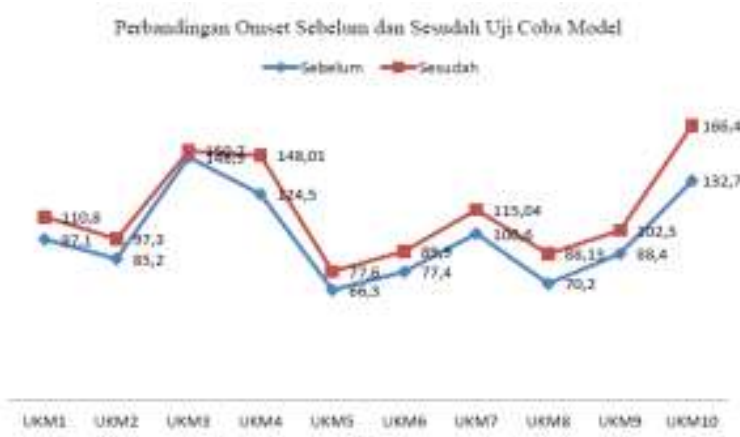

Sumber: Data Primer Diolah, 2016

Berdasarkan gambar 7, tentang rerata perkembangan penjualan setelah dilakukan uji coba model teoritik terungkap bahwa penjualan produk dari 10 (sepuluh) UKM yang dipilih secara acak mengalami peningkatan yang relatif siginifikan. Dalam kurun waktu lima bulan telah mengalami peningkatan pada hampir semua UKM tempat uji coba model. Sehingga untuk kategori usaha kecil, kinerja usaha sebagaimana ditujukkan pada gambar 2 tersebut sudah relatif cukup baik. Tentu hasil uji coba ini, secara empiris menguatkan model yang telah dikembangkan pada penelitian ini (gambar 1.) dan dapat dinyatakan sebagai model final dalam melakukan pemberdayaan usaha kecil menengah di Kota Probolinggo.

\section{Analisis Diskriminan}

Analisis diskriminan adalah teknik statistik multivariat yang digunakan untuk menggolongkan subyek pada satu kelompok. Prinsip diskriminan adalah ingin membuat model yang bisa secara jelas menunjukkan perbedaan (diskriminasi) antar isi variabel dependen, yang dalam kasus berikut adalah pangsa pasar usaha kecil dan usaha menengah. Untuk itu, langkah pertama pada 
analisis diskriminan adalah menguji apakah semua variabel independent (bebas) berbeda secara nyata berdasar variabel dependen. Selanjutnya, diketahui manakah indikator variabel yang menjadi prediktor signifikan. Secara jelas, berikut ini akan ditampilkan hasil-hasil analisis tentang tests of equality of group means dibawah ini.

Tabel 3. Test of Equality Of Group Means (Daya Saing)

\begin{tabular}{l|r|r|r|r|r}
\hline & Wilk' Lambda & F & dfl & df2 & Sig. \\
\hline Difereasiasi & 577 & 9.533 & 1 & 13 & 0.09 \\
\hline Immitatif & 504 & 10.170 & 1 & 13 & .008 \\
\hline Kennazulan Posisi & .688 & 8.633 & 1 & 13 & .024
\end{tabular}

Sumber: Data Primer Diolah, 2016

Berdasarkan tabel 3 terungkap bahwa baik posisi pasar, perkembangan pasar maupun proporsi pasar mempunyai signifikansi lebih kecil dari 0.05. Maknanya, daya saing ditentukan oleh ketiga indikator tersebut. Selanjutnya untuk variabel pencitraan korporasi, hasil analisis diskriminannya dijelaskan pada tabel 4 berikut.

Tabel 4. Test of Equality Of Group Means (Pencitraan)

\begin{tabular}{l|r|r|r|r|r} 
& Wills' Lambda & F & dfl & dE2 & Sig. \\
\hline Populeritas & 577 & 9.533 & 1 & 13 & 009 \\
\hline Persepsi Pasat & 483 & 13.839 & 1 & 13 & 003 \\
\hline Reputasi Korporasi & 572 & 9.380 & 1 & 13 & 008 \\
\hline Pand. Kompetitor & 998 & .021 & 1 & 13 & 887
\end{tabular}

Sumber: Data Primer diolah, 2016

Berdasarkan tabel 4 terungkap bahwa baik popularitas, persepsi pasar, reputasi korporasi mempunyai signifikansi lebih kecil dari 0.05 dan hanya pandangan kompetitor yang mempunyai signifikansi lebih besar dari 0.05. Maknanya, pencitraan ditentukan oleh ketiga indikator tersebut. Selanjutnya untuk variabel manajemen pengetahuan, hasil analisis diskriminannya dijelaskan pada tabel 5 berikut.
Tabel 5. Test of Equality Of Group Means (Manajemen Pengetahuan)

\begin{tabular}{l|r|r|r|r|r} 
& $\begin{array}{r}\text { Wills' } \\
\text { Lambda }\end{array}$ & $\mathrm{F}$ & dft & df: & Sig. \\
\hline Peagalaman & .577 & 9.533 & 1 & 13 & .009 \\
\hline Prosedur Keria & .483 & 13.889 & 1 & 13 & .003 \\
\hline Pengetalutan Intraet & .972 & 380 & 1 & 13 & 548
\end{tabular}

Sumber: Data Primer Diolah, 2016

Berdasarkan tabel 5 terungkap bahwa baik pengalaman dan prosedur kerja mempunyai signifikansi lebih kecil dari 0.05 dan hanya pengetahuan intranet yang mempunyai signifikansi lebih besar dari 0.05. Maknanya, manajemen pengetahuan ditentukan hanya oleh pengalaman dan prosedur kerja.Selanjutnya untuk variabel modal sosial, hasil analisis diskriminannya dijelaskan pada tabel 6 berikut.

Tabel 6. Test of Equality of Group Means (Modal Sosial)

\begin{tabular}{l|r|r|r|r|r} 
& Wilks' Lambda & $\mathrm{F}$ & dfl & df: & Sig. \\
\hline Share Vision & .577 & 9.533 & 1 & 13 & 009 \\
\hline Interaksi Sosial & 483 & 13.889 & 1 & 13 & 003 \\
\hline Kepenilikam Norma & .472 & 12.380 & 1 & 13 & 008 \\
\hline Silkns Kooneratif & .313 & 28.600 & 1 & 13 & 000
\end{tabular}

Sumber: data primer diolah, 2016

Berdasarkan tabel 6 terungkap bahwa semua prediktor modal sosoial dapat dinyatakan signifikan. Ha itu karena semuanya mempunyai signifikansi lebih besar dari 0.05. Dengan demikian, berdasarkan semua analisis diskriminan tersebut, maka model final yang adaptif adalah sebagai berikut:

Gambar 3. Model Final Pencitraan Korporasi dan Daya Saing

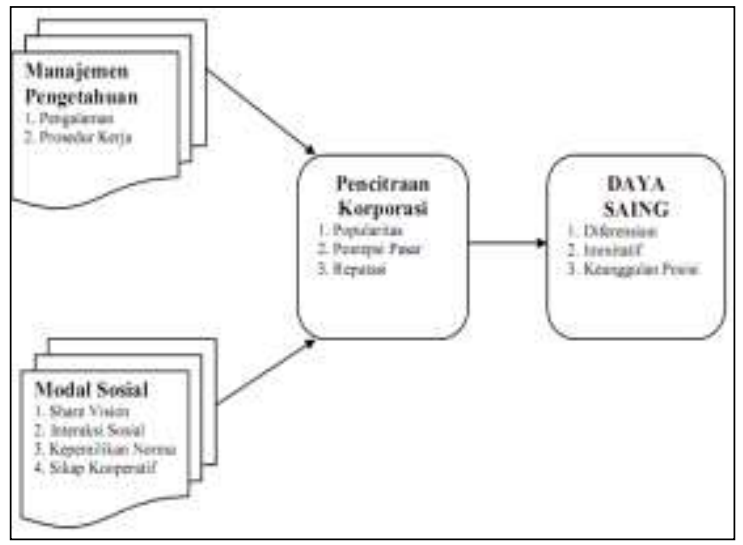


Dengan demikian, temuan ini sesuai hasil riset Vilvilaite dan Daubalite (2011) pada artikelnya Corporate Social Responsibility in Forming Corporate Image menyatakan bahwa corporate social responsibility secara empiris dapat membentuk pencitraan korporasi. Juga mendukung, Paradeniz (2009) dalam artikelnya The Important of Creating $A$ Successful Corporate Identity and Corporate Image for Entreprise in Marketing Management Performance, yang mengungkapkan bahwa corporate image mempunyai pengaruh besar dan signifikan terhadap kinerja bagian pemasaran, yang salah satu indikatornya menggunakan pangsa pasar. Sejalan dengan pendapat El Salam dan Shawky (2013) pada artikel hasil penelitiannya tentang The impact of corporate image and reputation on service quality, customer satisfaction and market share: testing the mediating role. Case analysis in an international service company.

Selain itu, memperkuat pendapat Servaes dan Tamayo (2013) pada artikelnya yang berjudul The Impact of Corporate Social Responsibility on Firm Value: The Role of Customer Awareness yang mengungkapkan bahwa social responsibility mempunyai pengaruh nyata tehadap nilai perusahaan, yang merupakan implikasi dari pertumbuhan pangsa pasar. Kemudian Neira et al.(2013) pada hasil risetnya tentang Social and human capital as determining factors of entrepreneurship in the Spanish Regions yang mengemukakan bahwa modal sosial sebagai penentu kemampuan berwirausaha. Penelitian ini menggunakan sampel sebanyak 270 pelaku usaha di Spanyol. Juga linear dengan ungkapan Stam, Arzaniang dan Elfring (2013) pada artikelnya tentang Social capital of entrepreneurs and small firm performance: Ameta-analysis of contextual and methodological moderators. Mendukung temuan Linli dan Chi Ci (2013) dalam artikel yang berjudul An Empirical Study of Corporate Brand Image, Customer Perceived Value and Satisfaction on Loyalty in Shoe Industry yang mengungkapkan, terdapat hubungan kuat antar variabel, utamanya corporate brand image dengan loyalitas pelanggan.

Memperkuat Markmalin \& Hakala (2012) pada artikelnya yang bejudul Customer Satisfaction Factors in Pakistan Internet Users Market yang menyatakan bahwa kepuasan pelanggan yang merupakan sasaran dari customer focus strategy mempunyai pengaruh signifikan terhadap pangsa pasar. Selanjutnya, mendukung Crebs (2008) dalam artikelnya yang berjudul Social Capital: The Key to Success for the $21^{\text {st }}$ organization, menjelaskan temuan sama bahwa manajemen jejaring yang memanfaatkn modal sosial, utamanya dalam kepemilikan kemampuan berkolaborasi memainkan peranan penting dalam membawa sebuah organisasi mewujudkan misi dan visinya. Juga, melengkapi pendapat Toumenin et all. (2013) pada artikelnya tentang Social Capital: A Source of Sustained Competitive Advantage for Consumer Co-operatives yang menyatakan bahwa modal sosial merupakan komponen penting untuk membangun keunggulan bersaing organisasi.

\section{KESIMPULAN}

Berdasarkan analisis inferensial dan hasil uji coba model pada (15) lima belas Usaha Kecil Menengah (UKM) di wilayah Kota Probolinggo terungkap jelas bahwa model yang diaplikasikan berdampak positip pada peningkatan penjualan, yang tentu sebagai salah satu indikator dari meningkatnya pangsa pasar sekaligus pencitraan usaha. Dengan demikian, model pencitraan korporasi dan daya saing melalui manajemen pengetahuan dan modal sosial yang telah didisain tersebut dapat digunakan pada semua usaha kecil khususnya yang melakukan kegiatan operasional usaha di Wilayah Kota Probolinggo. Tentu, berlangsungnya era perubahan yang terjadi, menuntut dilakukannya penyempurnaanan model secara periodik dan disesuaikan dengan dinamika perubahan prilaku pasar. Dengan demikian, implementasi model 
tersebut akan lebih berhasil dan berkontribusi lebih besar dalam meningkatkan pencitraan dan pangsa pasar menuju pada terwujudnya entitas usaha kecil yang makin berkembang.Yang yang jelas, Model pencitraan dan daya saing tersebut telah dapat dinyatakan sebagai model standar yang berkontribusi pada pengayaan ilmu manajemen.

\section{DAFTAR PUSTAKA}

Burt, Frederick, (2005), Measurement of Social Capital, The Third Edition, Ottawa University Publishing, Ottawa.

Cassidy, Edwin (2009), Knowledge Management, The First Edition, The Longman Publishing, Philadepia.

Coleman, Harry (2004), A Dimensional Approach to Measuring Social Capital: Development and Validation of a Social Capital Inventory, Sage Publication, Volme 42, Number 2, Reading University, London.

Colgate, Mark, 2009, Creating Sustainable Competitive Advantage Through Marketing Information System Technology: A Triangulation Methodology Within The Banking Industry, International Journal of Bank Marketing, Vol. 16/2

Cohen, James and Prusak, Tamadon (2003), Study of The Social Capital Dimensions, Creativity and Productivity, Journal of Social Capital, Volume 11, Number 7, March Edition, Melbourne University, Melbourne.

Day, George. S and Robin, Wensley, 2008, "Assesing Advantage : A Framework for Diagnosing Competitive Superiority", Journal of Marketing, Vol. 52, April.

Ferdinand, A. 2002. Structural Equation Modelling dalam Penelitian Manajemen. BP UNIDP. Semarang.

Fukuyama, Takada (2006), Social Capital in The Japanese Society, The Fourth Edition, Oklahoma University Lmt, Oklahoma.
Kosasih, Ida and Budiani, Sri (2008), The Knowledge Management in The Creative Industries, Jurnal of International Business Studies (JIBS), Volume 33, George Washington University, Washington.

Porter, Michael. E, 1993, Keunggulan Bersaing, Menciptakan dan Mempertahankan Kinerja Unggul, Erlangga, Jakarta.

Ramdani, M (2009), Pengembangan Modal Sosial, Inovasi dan Produktivitas, Jurnal Pskilogi Industri, Volume 18, No.5, Edisi Juni, Pusat Pengembangan Psikologi Terapan, Jakarta.

Stewet, Roger (2007), The Effect Talent Management to the Personal Creativity, Journal of Phsicology Management, Volume XX, No. 7, The Chicago University.

Yamin, S. dan Kurniawan, H., 2009, Structural Equation Modeling: Belajar Lebih Mudah Teknik Analisis Data Kuesioner dengan LISREL-PLS, Buku Seri Kedua, Jakarta: Salemba Infotek. 